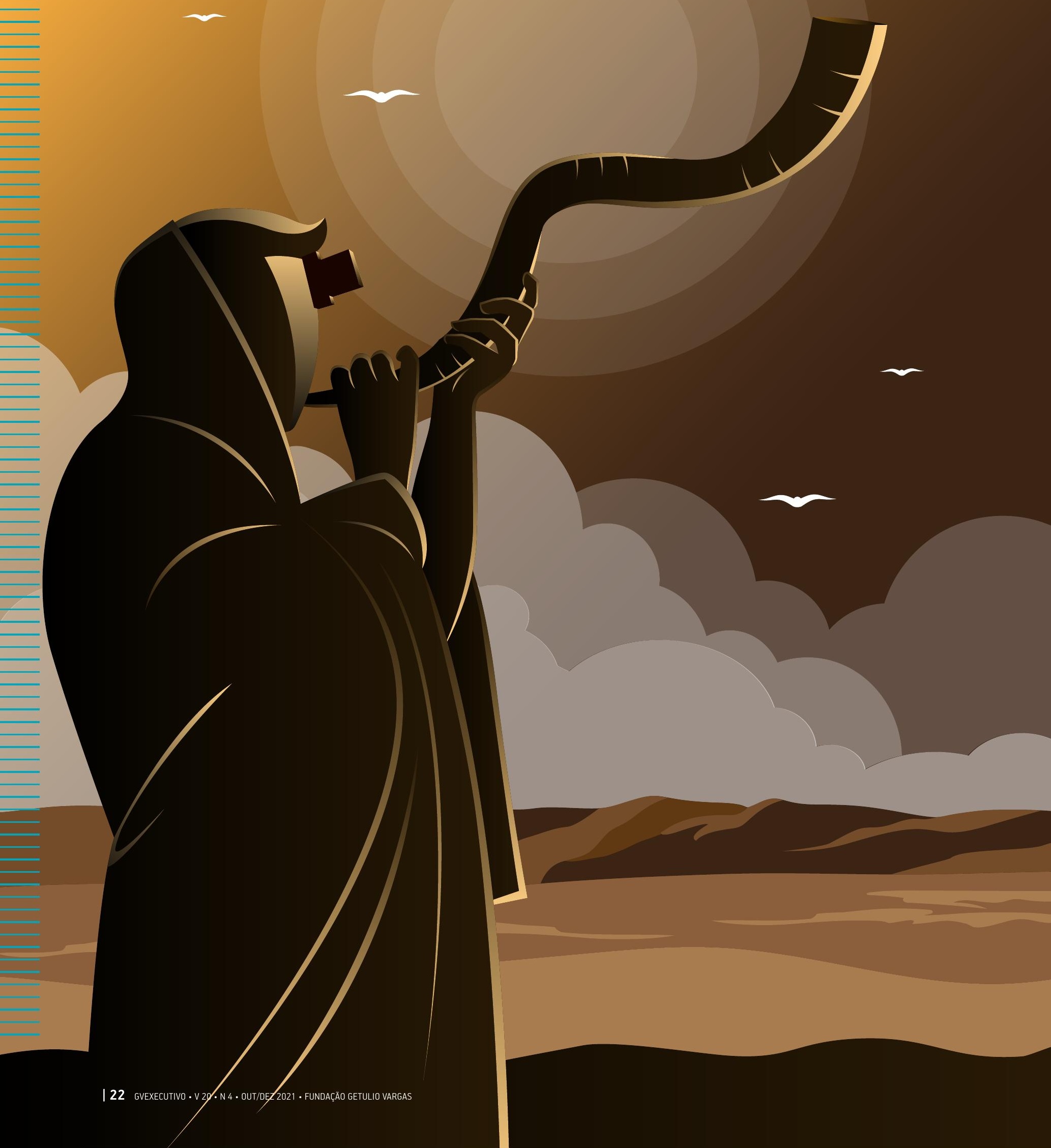




\section{ALÉM DA \\ BALANÇA COMERCIAL}

| POR RENATO OCHMAN

\section{Brasil e Israel intensificam os negócios na área de tecnologia, particularmente em agricultura, empreendedorismo e em soluções para cidades inteligentes.}

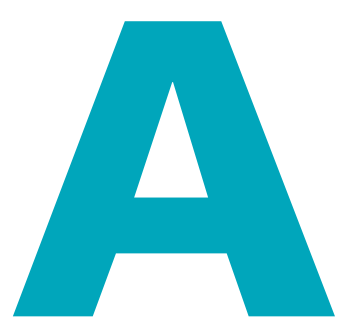

s relações comerciais entre Brasil e Israel têm sentido os efeitos de um impulso exponencial. A soma do comércio entre os dois países tem se mantido estável na faixa dos US\$ 1,5 bilhão ao ano, valor que reflete praticamente a faceta do intercâmbio de commodities. Mas o que esse número não mostra é o aumento de investimentos na área de tecnologia, tendência que tenho acompanhado de perto na liderança da Câmara de Comércio Brasil-Israel. Hoje já são 300 empresas israelenses fazendo negócios diretamente ou indiretamente com o Brasil - e há espaço para muito mais.

\section{AGRICULTURA}

Israel é atualmente o maior centro de tecnologia do mundo - com grande destaque para o agronegócio. Nesse setor, a cooperação de negócios entre Brasil e Israel pode, por exemplo, acelerar a jornada brasileira rumo ao posto de maior produtor mundial de alimentos. Tecnologias israelenses desenvolvidas e testadas em solo desértico in-
Hoje já são 300 empresas israelenses fazendo negócios diretamente ou indiretamente com o Brasil - e há espaço para muito mais.

cluem técnicas de irrigação agrícola, melhoramento de sementes e uso de drones no campo para colheita de frutas e para identificação de queimadas. Todas elas têm potencial para serem aplicadas por agricultores brasileiros, para que possam produzir mais gastando menos.

País que se desenvolveu em solo desértico, Israel teve que inovar para garantir água potável à população e para conseguir irrigar suas plantações. A inovação mais conhecida, sem dúvida, é o gotejamento, desenvolvida originalmente em um kibutz (comunidade agrícola) na década de 1960. 


\section{Tecnologias agrícolas israelenses incluem técnicas de irrigação agrícola, melhoramento de sementes e uso de drones no campo para colheita de frutas e para identificação de queimadas.}

O sucesso da técnica - que garante uma irrigação lenta e balanceada, gerando crescimento extraordinário das mudas - rendeu reputação internacional a Israel.

Além do gotejamento, outra técnica desenvolvida em Israel e que ganhou destaque mundial é a dessalinização. Muito associada à água do mar, ela também se aplica ao esgoto, tornando a água novamente potável e própria para o consumo. O método é similar nos dois casos, o que muda é o tanto de energia empenhada e o tipo de membrana usada na filtragem. A água dessalinizada em Israel responde por $75 \%$ do consumo doméstico. Na agricultura, cerca de $50 \%$ da água utilizada é resultado de tratamento de esgoto para geração de água de reúso. Hoje, o país detém $80 \%$ das exportações de produtos relacionados às tecnologias de irrigação, como o gotejamento, válvulas automáticas, controladores, filtração automática, entre outros.

\section{EMPREENDEDORISMO}

A capacidade de inovação dos israelenses também está por trás do fato de Israel ser hoje uma startup nation (veja artigo de Gilberto Sarfati sobre o tema nesta edição). O país conta com mais de 70 unicórnios, acumula 12 prêmios Nobel e investe $9,2 \%$ de seu produto interno bruto (PIB) em educação, um pilar muito importante da cultura israelense. O resultado é que cerca de $50 \%$ das empresas listadas na Nasdaq (National Association of Securities Dealers Automated Quotations, bolsa de valores dos Estados Unidos que concentra as empresas de tecnologia) têm líderes formados pelo Technion - Israel Institute of Technology.

Em 2020, as startups israelenses atraíram 10 bilhões de dólares em investimentos, uma alta de $30 \%$ em relação ao ano anterior. A gestora brasileira Mindset Ventures, por exemplo, nasceu captando recursos para investir em empresas de Israel. Mas como o mercado consumidor israe- lense é pequeno, a gestora passou a também levar a operação das empresas investidas para o Brasil. Em sua última captação, em janeiro deste ano, a Mindset Ventures levantou 45 milhões de dólares para aplicar primordialmente em empresas dos EUA e de Israel.

O caminho inverso também tem potencial. Há grande interesse dos investidores israelenses em startups brasileiras, especialmente do agronegócio e de cibersegurança, setores considerados prioritários em Israel. Além disso, a Câmara de Comércio Brasil-Israel realiza cerca de cinco missões por ano para ajudar empresas brasileiras a ingressarem no mercado israelense. Além de um ambiente favorável aos negócios, empreendedores encontram em Israel acesso a opções de financiamento via fundos de venture capital e podem contar com um valuation de suas companhias até cinco vezes maior em relação ao que conseguiriam no Brasil.

Um exemplo de empreendimento que se estabeleceu em Israel é a empresa paranaense Superbac, que trabalha com soluções biotecnológicas. A Superbac decidiu empreender em Israel em 2016 e hoje trabalha em uma estação de tratamento de efluentes em Jerusalém. Nesse meio tempo, mais de dez empresas israelenses e de outras nacionalidades já usaram as soluções oferecidas pela companhia no país. Além do trabalho em Jerusalém, a Superbac está expandindo suas atividades a uma cidade próxima chamada Hod Hadsharon, para atuar com a geração de biogás. Outras empresas brasileiras estabelecidas em Israel são H. Stern, Suzano Papel e Celulose, Consist e Padtec.

\section{SMART CITIES}

Outra frente de inovação em que Israel vem despontando e interessa a todos quando se pensa na vida pós-pandemia diz respeito às smart cities. Tel Aviv, por exemplo, está desenvolvendo-se rapidamente como uma cidade inteligente, 


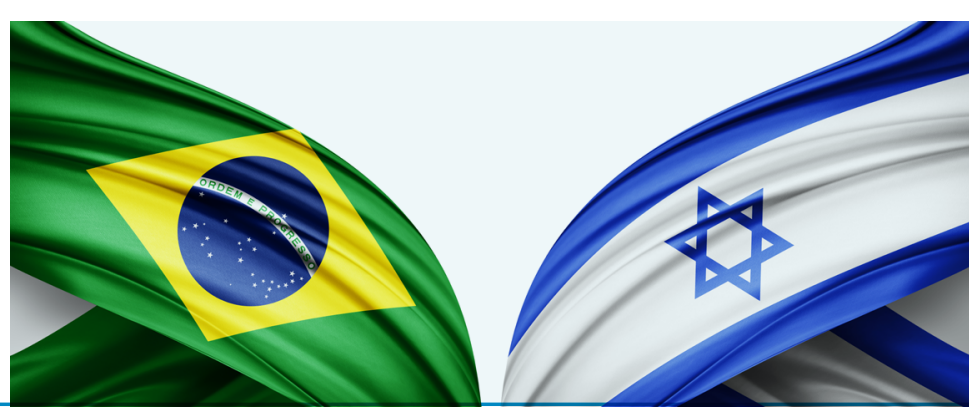

\section{LAÇOS HISTÓRICOS}

As relações entre Brasil e Israel são tão antigas quanto a própria fundação de Israel, em 1948. Vale lembrar que, em 1947, o diplomata brasileiro Oswaldo Aranha presidiu a Assembleia Geral da Organização das Nações Unidas que tomou a decisão histórica de partilha da Palestina, levando à formação do Estado de Israel no ano seguinte.

Desde então, os dois países compartilham conhecimento e tecnologia em diferentes áreas, desde o agronegócio até a produção cultural. Um marco nas relações comerciais entre Brasil e Israel foi o Acordo de Livre Comércio entre Israel e o Mercosul, o primeiro entre o bloco e um país de fora da região. Ele foi firmado em dezembro de 2007 e entrou em vigor a partir de abril de 2010, prevendo a redução de tarifas alfandegárias de uma lista de 9.750 produtos de Israel para importação pelo Mercosul e 8.866 produtos na mão oposta. Além do intercâmbio comercial, o acordo abriu os dois mercados para a cooperação em relação a normas técnicas, sanitárias e fitossanitárias, regras de origem, salvaguardas, além de cooperação tecnológica, técnica e aduaneira.

Israel vem desenvolvendo tecnologias para cidades inteligentes de integração de serviços urbanos, de segurança contra ataques cibernéticos e de softwares que utilizam iluminação LED imobiliária para coletar, analisar e monetizar dados.

e seguem no mesmo ritmo empresas do país que estão se especializando e fornecendo soluções para o mundo. Elas estão trabalhando principalmente com desenvolvimento de infraestruturas tecnológicas que permitam a implementação e integração de serviços urbanos inteligentes de forma rápida e econômica; segurança contra ataques cibernéticos em aplicações que usam internet das coisas (IoT); e soluções de software que utilizam iluminação LED imobiliária para coletar, analisar e monetizar dados valiosos para cidades inteligentes. Globalmente, esse é um mercado estima- do em 124 bilhões de dólares em 2020, de acordo com relatório da consultoria IDC, e que não para de crescer: o valor foi $18,9 \%$ superior em relação a 2019.

No Brasil, há muito mercado para esse tipo de solução urbana inteligente. As cidades de São Paulo, Florianópolis, Curitiba e Campinas estão um passo à frente nessa jornada, seguindo o caminho de grandes metrópoles globais dos Estados Unidos, Europa Ocidental e China.

Seja no agronegócio, via startups inovadoras ou pelas soluções para smart cities, a tecnologia israelense está cada vez mais presente em nosso dia a dia. Olhando além dos números da balança comercial, os ventos sopram a favor de bons negócios entre os dois países.

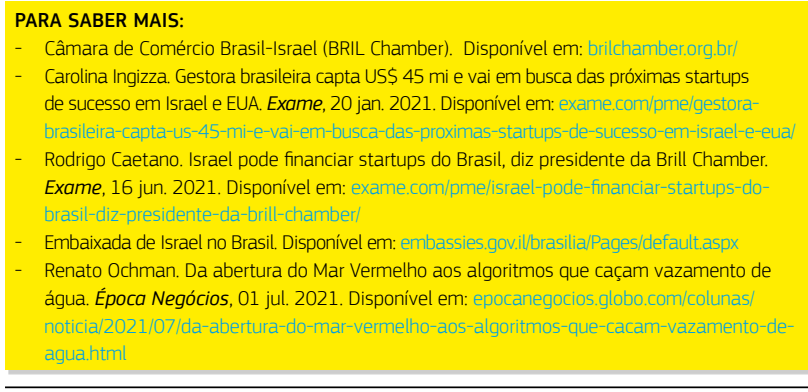

Renato Ochman > Presidente da Câmara de Comércio Brasil-Israel (BRIL Chamber) > renato@ochmanadv.com.br 